Bài báo khoa học

\title{
Đánh giá tài nguyên khí hậu nông nghiệp và tác động đến sinh kế trồng trọt vùng đồng bằng ven biển Bắc Trung Bộ
}

\author{
Nguyễn Hồng Sơn ${ }^{1 *}$, Dương Văn Khảm ${ }^{1}$ \\ 1 Viện Khoa học Khí tượng Thủy văn và Biến đổi khí hậu; nguyenson.imh@gmail.com; \\ kham.duongvan@imh.ac.vn \\ *Tác giả liên hệ: nguyenson.imh@gmail.com; Tel.: +84-914888185
}

Ban Biên tập nhận bài: 12/7/2021; Ngày phản biện xong: 16/8/2021; Ngày đăng bài: $25 / 10 / 2021$

Tóm tắt: Điều kiện thời tiết và khí hậu có liên quan chặt chẽ với sinh kế trồng trọt trước hết là ánh sáng, nhiệt độ và nước. Đó là những yếu tố không thể thiếu và thay thế được đối với sự sống nói chung, sự sinh trưởng, phát triển và cấu thành năng suất cây trồng nói riêng. Vì vậy, việc đánh giá một cách có hệ thống các điều kiện khí hậu nông nghiệp sẽ giúp cho các nhà quản lý, chỉ đạo sản xuất nắm bắt được mức độ thuận lợi của nguồn tài nguyên khí hậu và những trở ngại của các thiên tai, thời tiết bất lợi gây ra đối với sinh kế trồng trọt. Bài báo sử dụng số liệu quan trắc thời kỳ 1985-2020 tại các trạm khí tượng và phương pháp thống kê để tính toán, phân tích diễn biến theo không gian và thời gian của các yếu tố khí hậu nông nghiệp, thời tiết bất lợi và tác động đến phân bố, thời vụ và năng suất cây trồng ở vùng đồng bằng ven biển Bắc Trung Bộ. Kết quả của bài báo là cơ sở khoa học cho việc phát triển nông nghiệp nói chung và trồng trọt nói riêng ở vùng nghiên cứu.

Từ khoá: Tài nguyên khí hậu nông nghiệp; Tác động đến sinh kế trồng trọt; Ven biển Bắc Trung Bộ.

\section{1. Đặt vấn đề}

Để hỗ trợ cho sự phát triển kinh tế, xóa đói giảm nghèo ở các vùng nông thôn, đặc biệt là các vùng ven biển đã có nhiều công trình nghiên cứu, hoạt động của các tổ chức phi chính phủ góp phần không nhỏ giúp người dân đảm bảo an ninh sinh kế, giảm tính dễ bị tổn thương, tăng cường khả năng chống chịu trước sự thay đổi bất thường của thời tiết, khí hậu. Các mô hình, sáng kiến này đã cho thấy sự thay đổi rõ rệt về thu nhập, ổn định cuộc sống của người dân.

Kết quả tổng hợp và đánh giá về các mô hình sinh kế do các tổ chức phi chính phủ triển khai tại Việt Nam của Trung tâm Phát triển Nông thôn bền vững [1] đã cho thấy: Hầu hết các dự án sinh kế thường tập trung trong các lĩnh vực sản xuất nông nghiệp, nuôi trồng thủy sản kết hợp với nâng cao năng lực cho cộng đồng và cải thiện một phần sinh kế và điều kiện sinh hoạt của người dân. Tuy nhiên, các tài liệu này cũng chỉ ra rằng:

- Các mô hình/sáng kiến sinh kế còn thiếu minh chứng, luận cứ khoa học. Các mô hình, sáng kiến trong các dự án NGOs thường xuất phát nhu cầu của người dân hoặc được giới thiệu bởi dự án, học hỏi qua kinh nghiệm của các đơn vị, các tổ chức khác. Việc hình thành và phát triển các mô hình, sáng kiến này chưa dựa trên những phân tích đánh giá một cách có khoa học về những tác động hiện có và tiềm tàng của biến đổi khí hậu địa phương. Chính vì thế mà rất nhiều các mô hình được đưa ra, các tác giả chưa đưa được nhiều những 
cơ sở khoa học vững chắc để minh chứng khả năng thích ứng với điều kiện thời tiết, khí hậu cũng như biến đổi khí hậu của các mô hình, sáng kiến này.

- Những đánh giá về mô hình hiện nay tập trung phân tích tính hiệu quả về tăng năng suất, thu nhập, tiết kiệm chi phí hay đa dạng hóa sinh kế,... những yếu tố này sẽ gián tiếp làm tăng khả năng ứng phó và phục hồi của người dân trong điều kiện khí hậu thay đổi. Các diễn giải về khả năng thích ứng hay giảm thiểu được dựa trên những phân tích từ các luận cứ mang tính lý thuyết. Chưa có mô hình nào đưa ra những thông tin cụ thể và số liệu thống kê một cách có hệ thống về việc cải thiện khả năng thích ứng của người dân đối với một tác động cụ thể của thời tiết khí hậu hay biến đổi khí hậu. Chẳng hạn như cây trồng, thời vụ phù hợp, khả năng luân canh,...

Như vậy, có thể nhận thấy việc nghiên cứu, đánh giá tài nguyên khí hậu nông nghiệp (KHNN) là cơ sở khoa học để cung cấp các thông tin cần thiết cho quy hoạch phát triển nông nghiệp. Việc đánh giá có hệ thống các điều kiện $K H N N$, so sánh mức bảo đảm của chúng với yêu cầu của cây trồng đối với khí hậu là rất quan trọng từ đó làm cơ sở phân vùng KHNN có ý nghĩa quyết định trong việc hình thành các vùng sản xuất nông nghiệp [2], sử dụng hợp lý tài nguyên khí hậu ở các tiểu vùng sinh thái, bố trí cây trồng, cơ cấu luân canh và thời vụ phù hợp nhằm khai thác được lợi thế tiềm năng về tài nguyên, né tránh thiên tai và đạt năng suất, chất lượng nông sản cao nhất và phát triển bền vững [3].

Vùng đồng bằng ven biển Bắc Trung Bộ có địa hình chia cắt mạnh, sự phân hóa sâu sắc theo không gian và thời gian của chế độ khí hậu và sự tác động mạnh mẽ của biến đổi khí hậu toàn cầu đã làm cho thiên tai có nguồn gốc từ khí hậu ở đây đang ngày một khốc liệt và có chiều hướng gia tăng. Bão, áp thấp nhiệt đới, mưa lớn gây ra lũ lụt, lũ quét, trong mùa mưa, khô hạn trong mùa khô đã gây thiệt hại trực tiếp hàng trăm tỷ đồng, để lại những hậu quả xấu về môi trường. Vì vậy, nông nghiệp vùng ven biển Bắc Trung Bộ chỉ thực sự phát triển bền vững khi được quy hoạch một cách tổng thể. Về sản xuất nông nghiệp hay xây dựng các mô hình sinh kế cần được quy hoạch thành các vùng chuyên canh với diện tích ổn định.

Đánh giá tài nguyên KHNN được tiến hành ở nhiều nước trên thế giới, theo nghiên cứu [4-5], đánh giá tài nguyên $\mathrm{KHNN}$ được tiến hành từ đầu thế kỷ $\mathrm{XX}$ và đến giữa thế kỷ $\mathrm{XX}$, các công trình nghiên cứu của các nhà khoa học Liên Xô cũ đã đưa một bước tiến mới trong đánh giá tài nguyên khí hậu nông nghiệp. Hiện nay, các phương pháp đánh giá tài nguyên KHNN [6-8] được nhiều nước áp dụng rộng rãi. Tại Việt Nam, các nghiên cứu về tài nguyên khí hậu, KHNN nổi bật được tiến hành từ năm 1980 [9-14]. Các nghiên cứu đánh giá tài nguyên khí hậu, KHNN dựa trên mạng lưới trạm quan trắc khí tượng cơ bản trên toàn quốc. Các phương pháp, chỉ tiêu đánh giá tài nguyên KHNN được kế thừa và áp dụng của các công trình nghiên cứu trên thế giới. Năm 2016, [15] đã ứng dụng dữ liệu viê̂n thám kết hợp dữ liệu quan trắc mặt đất trong nghiên cứu đánh giá tài nguyên KHNN. Kết quả của các công trình nghiên cứu đã đóng góp được những cơ sở khoa học trong khai thác, sử dụng hợp lý tài nguyên khí hậu, KHNN cho phát triển kinh tế-xã hội ở Việt Nam. Các nghiên cứu tập trung ở quy mô cả nước, cấp vùng, chưa chi tiết hóa thông tin KHNN cho các tiểu vùng nhỏ (cấp huyện).

Nhằm cung cấp cơ sở khoa học để khai thác và sử dụng hợp lý tài nguyên KHNN ở các huyện vùng đồng bằng ven biển Bắc Trung Bộ, bài báo kế thừa các phương pháp đánh giá tài nguyên khí hậu, KHNN của WMO, $\mathrm{FAO}$ và các công trình nghiên cứu tại Việt Nam để chi tiết hóa tài nguyên KHNN cho các huyện vùng nghiên cứu.

\section{Số liệu và phương pháp nghiên cứu}

\subsection{Giới hạn không gian nghiên cứu}

Các huyện ven biển: Nga Sơn, Hậu Lộc, Hoằng Hóa, TX Sầm Sơn, Quảng Xương, Tĩnh Gia (tỉnh Thanh Hóa); Quỳnh Lưu, Diễn Châu, Nghi Lộc, TX Cửa Lò (tỉnh Nghệ An); Nghi Xuân, Lộc Hà, Thạch Hà, Cẩm Xuyên, Kỳ Anh (tỉnh Hà Tĩnh (Hình 1). 


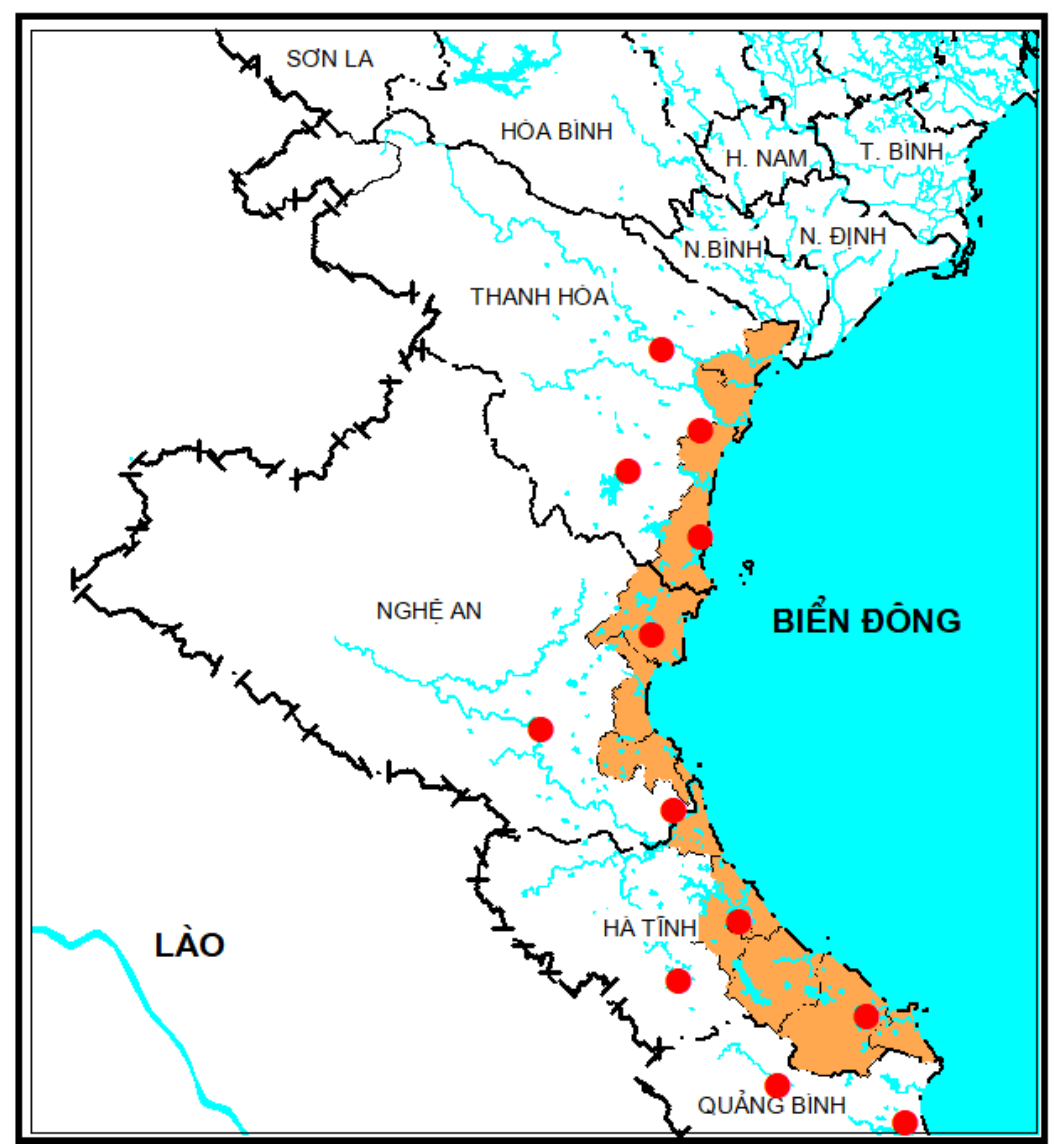

Hình 1. Sơ đồ mạng lưới trạm quan trắc cơ bản và khu vực nghiên cứu.

\subsection{Số liệu tính toán}

- Số liệu khí tượng: số liệu 12 trạm khí tượng cơ bản vùng nghiên cứu bao gồm các yếu tố: lượng mưa; nhiệt độ không khí trung bình, nhiệt độ không khí tối cao, nhiệt độ không khí tối thấp; độ ẩm không khí trung bình; độ ẩm không khí tối thấp, bốc hơi, gió, nắng từ năm 1985 đến 2020.

- Các tài liệu, số liệu về sản xuất nông nghiệp: Diện tích, năng suất, sản lượng, cơ cấu thời vụ của các cây trồng vùng nghiên cứu [16-18]

\subsection{Phuơng pháp tính toán}

Các chỉ tiêu KHNN biểu hiện định lượng nhu cầu của cây trồng đối với điều kiện khí hậu của môi trường quanh chúng trong suốt thời gian sinh trưởng. Các chỉ tiêu này được phân thành các nhóm chính sau $[3-8,10,15]$ :

- Chỉ tiêu về ánh sáng, tài nguyên bức xạ: độ dài ngày, bức xạ quang hợp, số giờ nắng

- Chỉ tiêu về tài nguyên nhiệt: nhiệt độ không khí trung bình tháng và năm; ngày bắt đầy, kết thúc các đợt rét hại; ngày bắt đầy, kết thúc mùa lạnh; ngày bắt đầy, kết thúc mùa nóng; tổng nhiệt độ; nhiệt độ không khí tối thấp tuyệt đối trung bình năm.

- Chỉ tiêu về tài nguyên ẩm: phân bố mưa và đặc trưng mùa mưa; ngày bắt đầu, kết thúc mùa mưa; lượng mưa tích lũy trước và sau mốc đã chọn; xác suất 2,3 tuần khô liên tục.

Trên cơ sở các chuỗi số liệu được thu thập từ các trạm khí tượng cơ bản trong và lân cận vùng nghiên cứu, bằng các phương pháp thống kê trong khí hậu [18], KHNN [6-7, 2022] để tính toán các đặc trưng thống kê: trung bình số học; tổng số; cao nhất, thấp nhất của chuỗi, bức xạ quang hợp; suất bảo đảm; ngày bắt đầu, kết thúc, xác suất. 


\section{Kết quả và thảo luận}

\section{1. Đánh giá tài nguyên khí hậu nông nghiệp vùng ven biển Bắc Trung Bộ}

\subsubsection{Tài nguyên ánh sáng và bức xạ quang hợp}

a) Độ dài ngày

Ánh sáng bức xạ mặt trời nói chung và độ dài ngày nói riêng rất có ý nghĩa trong việc chọn tạo giống cây trồng để đưa vào những vùng cần thiết, đặc biệt đối với cây trồng có phản ứng với độ dài ngày. Độ dài ngày ở một vĩ độ không đổi nhưng thay đổi theo thời gian và theo mùa.

Bảng 1 cho thấy khu vực ven biển Bắc Trung Bộ kéo dài từ $20^{\circ} 06^{\prime}$ đến $17^{\circ} 63^{\prime}$ nên độ dài ngày không có sự thay đổi lớn, độ dài ngày chỉ thay đổi ở các tháng chính đông và chính hè khoảng 2,2 giờ.

Bảng 1. Độ dài ngày (giờ) tại các trạm khí tượng [4-5].

\begin{tabular}{lcccccccccccc}
\hline \multirow{2}{*}{ Trạm } & \multicolumn{10}{c}{ Tháng } \\
\cline { 2 - 12 } & I & II & III & IV & V & VI & VII & VIII & IX & X & XI & XII \\
\hline Thanh Hóa & 10,9 & 11,4 & 11,9 & 12,5 & 12,9 & 13,2 & 13,1 & 12,7 & 12,1 & 11,5 & 11,0 & 10,8 \\
Vinh & 11,0 & 11,4 & 11,9 & 12,4 & 12,9 & 13,1 & 13,0 & 12,6 & 12,1 & 11,6 & 11,1 & 10,9 \\
Kỳ Anh & 11,0 & 11,4 & 11,9 & 12,4 & 12,9 & 13,1 & 13,0 & 12,6 & 12,1 & 11,6 & 11,1 & 10,9 \\
\hline
\end{tabular}

b) Bức xạ quang hợp

Bức xạ mặt trời đặc biệt quan trọng trong nông nghiệp. Thứ nhất ánh sáng là nguồn năng lượng mà cây xanh chuyển thành năng lượng hoá học. Thứ hai, bức xạ là nguồn năng lượng chính trong quá trình bốc hơi, quyết định nhu cầu nước của cây trồng. Qua bảng 2 cho biết đối với vùng ven biển Bắc Trung Bộ $\mathrm{PAR}$ tương đối cao vào mùa hè, cao nhất vào các tháng $\mathrm{V}, \mathrm{VI}$, VII và tương đối thấp vào mùa đông, thấp nhất vào các tháng XI, XII, I.

Bảng 2. Bức xạ quang hợp ( $\mathrm{Kcal} / \mathrm{cm}^{2}$.tháng) tại các trạm có đo bức xạ.

\begin{tabular}{lcccccccccccc}
\hline \multirow{2}{*}{ Trạm } & \multicolumn{10}{c}{ Tháng } \\
\cline { 2 - 13 } & I & II & III & IV & V & VI & VII & VIII & IX & X & XI & XII \\
\hline Thanh Hóa & 2,9 & 2,4 & 3,0 & 4,4 & 7,0 & 6,8 & 7,8 & 6,7 & 5,5 & 5,0 & 3,5 & 3,3 \\
Vinh & 2,8 & 2,4 & 3,1 & 4,9 & 7,2 & 7,1 & 8,0 & 7,0 & 5,7 & 4,5 & 3,2 & 2,9 \\
Kỳ Anh & 3,2 & 2,8 & 3,6 & 5,6 & 7,4 & 7,4 & 8,1 & 7,2 & 5,6 & 4,5 & 3,0 & 3,1 \\
\hline
\end{tabular}

3) Số giờ nắng

Trên bảng 3 , tháng $\mathrm{II}$ là tháng có số giờ nắng thấp nhất trong năm (từ 1,5 đến 2 giờ/ngày), cao nhất là tháng VII, VIII (6-7 giờ/ngày).

Bảng 3. Tổng số giờ nắng (giờ) tháng.

\begin{tabular}{lcccccccccccc}
\hline \multirow{2}{*}{ Trạm } & \multicolumn{10}{c}{ Tháng } \\
\cline { 2 - 12 } & I & II & III & IV & V & VI & VII & VIII & IX & X & XI & XII \\
\hline Thanh Hóa & 84,3 & 50,7 & 57,1 & 109,4 & 198,1 & 190,5 & 209,9 & 173,6 & 167,6 & 171,1 & 131,1 & 126,2 \\
Vinh & 71,2 & 49,3 & 69,6 & 132,6 & 212,0 & 198,5 & 207,5 & 177,5 & 158,6 & 133,8 & 96,8 & 85,9 \\
Kỳ Anh & 78,7 & 60,1 & 94,5 & 152,5 & 226,5 & 221,7 & 241,5 & 195,7 & 162,7 & 125,7 & 80,6 & 75,3 \\
\hline
\end{tabular}

\subsubsection{Tài nguyên nhiệt}

1) Nhiệt độ trung bình tháng và năm

Biến trình nhiệt độ không khí trung bình vùng nghiên cứu có một cực đại vào tháng chính hè (tháng VII) và một cực tiểu vào các tháng chính đông (tháng I). 


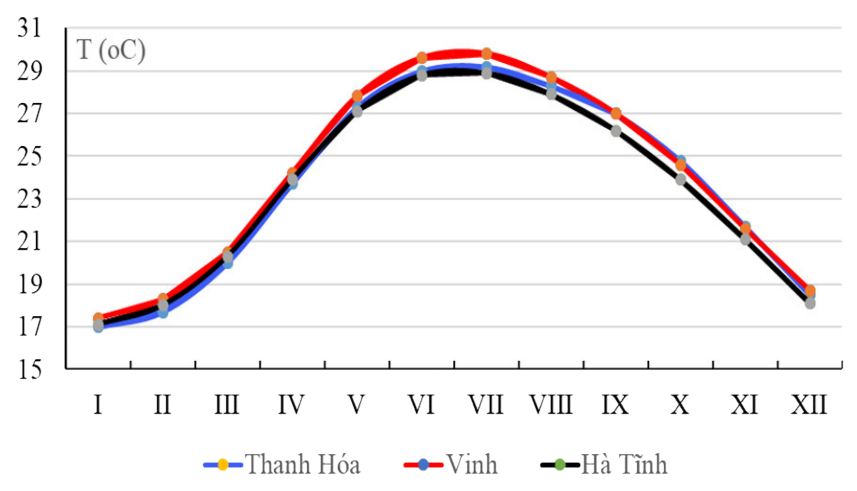

Hình 2. Biến trình nhiệt độ không khí tại các trạm quan trắc.

Trên bảng 4 cho thấy nhiệt độ không khí trung bình năm $\left(\mathrm{T}_{\text {tbnăm}}\right)$ vùng nghiên cứu

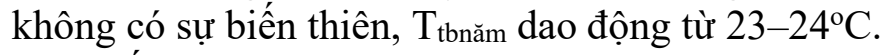

Biến trình nhiệt độ không khí trung bình vùng nghiên cứu có một cực đại vào tháng chính hè (tháng VII hoặc tháng VI hay tháng VIII) và một cực tiểu vào các tháng chính

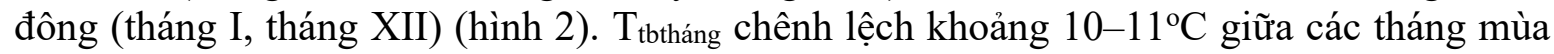

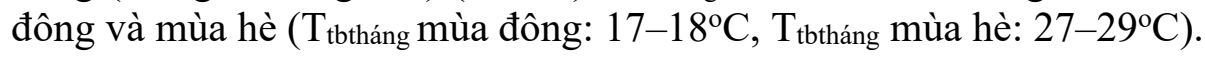

Bảng 4. Nhiệt độ không khí TBNN $\left({ }^{\circ} \mathrm{C}\right)$ của các tháng tại một số trạm.

\begin{tabular}{|c|c|c|c|c|c|c|c|c|c|c|c|c|c|}
\hline \multirow{2}{*}{ Trạm } & \multicolumn{12}{|c|}{ Tháng } & \multirow{2}{*}{$\begin{array}{c}\text { TB } \\
\text { năm }\end{array}$} \\
\hline & I & II & III & IV & $\mathbf{V}$ & VI & VII & VIII & IX & $\mathbf{X}$ & XI & XII & \\
\hline Thanh Hóa & 17,0 & 17,7 & 20,0 & 23,7 & 27,3 & 29,0 & 29,2 & 28,3 & 27,0 & 24,8 & 21,7 & 18,5 & 23,7 \\
\hline Vinh & 17,4 & 18,3 & 20,5 & 24,2 & 27,8 & 29,6 & 29,8 & 28,7 & 27,0 & 24,6 & 21,6 & 18,7 & 24,0 \\
\hline Kỳ Anh & 17,9 & 18,5 & 20,9 & 24,6 & 28,0 & 29,7 & 29,9 & 28,9 & 26,9 & 24,5 & 21,6 & 18,8 & 24,2 \\
\hline
\end{tabular}

2) Nhiệt độ tối cao và tối thấp

Tương tự như biến trình của nhiệt độ không khí trung bình, nhiệt độ tối cao $\left(\mathrm{T}_{\max }\right)$ và tối thấp $\left(\mathrm{T}_{\min }\right)$ cũng có một cực đại vào tháng VII và một cực tiểu vào tháng $\mathrm{I}$. Do bị ảnh hưởng nhiều của các đợt gió tây khô nóng, vì vậy $\mathrm{T}_{\max }$ tuyệt đối cao nhất cả nước: 40 $43^{\circ} \mathrm{C}$, xảy ra vào các tháng mùa hè. Trong các tháng mùa đông, do ảnh hưởng của gió mùa đông Bắc, có $\mathrm{T}_{\min }$ tuyệt đối dao động từ $2-6^{\circ} \mathrm{C}$.

3) Một số chỉ tiêu về nhiệt độ

a) Ngày bắt đầu và kết thúc các đợt rét hại

Từ bảng 5 cho thấy đồng bằng ven biển Bắc Trung Bộ thời gian rét hại thường bắt đầu vào đầu vào thượng tuần tháng XII với $\mathrm{SBĐ} 20 \%$ và kết thúc trung tuần tháng II với $\mathrm{SB} Đ$ $80 \%$, thời gian kéo dài từ $1-1,5$ tháng.

Bảng 5. Ngày bắt đầu và kết thúc rét hại.

\begin{tabular}{clccccc}
\hline STT & Trạm & $\begin{array}{c}\text { Ngày bắt đầu } \\
\text { trung bình (SBĐ } \\
\mathbf{5 0 \% )}\end{array}$ & $\begin{array}{c}\text { Ngày bắt } \\
\text { dầu với } \\
\text { SBĐ 20\% }\end{array}$ & $\begin{array}{c}\text { Ngày kết thúc } \\
\text { trung bình (SBĐ } \\
\mathbf{5 0 \%}\end{array}$ & $\begin{array}{c}\text { Ngày kết } \\
\text { thúc với } \\
\text { SĐB 80\% }\end{array}$ & $\begin{array}{c}\text { Thời gian } \\
\text { kéo dài } \\
\text { (ngày) }\end{array}$ \\
\hline 1 & Thanh Hóa & $12 / \mathrm{I}$ & $28 / \mathrm{XII}$ & $01 / \mathrm{II}$ & $14 / \mathrm{II}$ & 50 \\
2 & Vinh & $13 / \mathrm{I}$ & $28 / \mathrm{XII}$ & $30 / \mathrm{I}$ & $12 / \mathrm{II}$ & 43 \\
3 & Kỳ Anh & $16 / \mathrm{I}$ & $3 / \mathrm{I}$ & $4 / \mathrm{II}$ & $13 / \mathrm{II}$ & 41 \\
\hline
\end{tabular}

b) Ngày bắt đầu và kết thúc mùa đông lạnh

Biết rằng thời kỳ có nhiệt độ xuống dưới $20^{\circ} \mathrm{C}$ là mùa lạnh và là thời kỳ sinh trưởng của các cây trồng xứ lạnh như khoai tây, lúa mì, mạch (một số giống), rau, đậu đỗ ôn đới. Kết quả tính toán vùng nghiên cứu được thể hiện trên bảng 6 . 
Thời kỳ mùa đông vùng ven biển Thanh Hóa kéo dài đến 4 tháng (từ trung tuần tháng XI đến trung tuần tháng III) và giảm dần đến vùng ven biển Hà Tĩnh chỉ còn khoảng trên 3 tháng.

Bảng 6. Ngày bắt đầu mùa lạnh (qua $20^{\circ} \mathrm{C}$ thời kỳ giảm) của một số trạm đại diện các vùng với các suất bảo đảm khác nhau.

\begin{tabular}{lccccccc}
\hline & \multicolumn{9}{c}{ Suất bảo đảm (\%) } & Thò̀ gian \\
\cline { 2 - 7 } Trạm & \multicolumn{3}{c}{ Ngày bắt đầu } & \multicolumn{3}{c}{ Ngày kết thúc } & kéo dài \\
& $\mathbf{2 0}$ & $\mathbf{5 0}$ & $\mathbf{8 0}$ & $\mathbf{2 0}$ & $\mathbf{5 0}$ & $\mathbf{8 0}$ & (ngày) \\
\hline Thanh Hóa & $01 / \mathrm{XI}$ & $14 / \mathrm{XI}$ & $28 / \mathrm{XI}$ & $12 / \mathrm{III}$ & $11 / \mathrm{III}$ & $26 / \mathrm{III}$ & 117 \\
Vinh & $30 / \mathrm{X}$ & $12 / \mathrm{XI}$ & $26 / \mathrm{XI}$ & $11 / \mathrm{III}$ & $14 / \mathrm{III}$ & $26 / \mathrm{III}$ & 116 \\
Kỳ Anh & $20 / \mathrm{XI}$ & $30 / \mathrm{XI}$ & $13 / \mathrm{XII}$ & $28 / \mathrm{II}$ & $13 / \mathrm{III}$ & $20 / \mathrm{III}$ & 104 \\
\hline
\end{tabular}

c) Ngày bắt đầu và kết thúc mùa nóng

Mùa nóng là mùa có nhiệt độ trung bình ngày đêm của không khí lớn hơn hoặc bằng $25^{\circ} \mathrm{C}$. Đối với sản xuất nông nghiệp đây là những mốc thời gian quan trọng để xác định thời kỳ trỗ bông, ra hoa, làm hạt của nhiều loại cây trồng nhiệt đới mà điển hình là cây lúa.

Ở vùng ven biển Bắc Trung Bộ, nơi chịu ảnh hưởng của gió tây rất khô và nóng nên làm cho ngày bắt đầu và kết thúc mùa nóng ở đây bất ổn định nhất. Tuỳ thuộc sự hoạt động của hệ thống gió tây, trong từng năm, ngày chuyển mức nhiệt độ qua thời kỳ nóng có thể sớm hơn hoặc muộn hơn tới 20 ngày xung quanh ngày trung bình. Trong đại đa số các năm (với suất bảo đảm $80 \%$ ) độ lệch cũng đạt tới 10-12 ngày. Từ bảng 7 cho thấy: khu vực Bắc Trung Bộ thường bắt đầu vào đầu tháng IV và kết thúc vào đầu tháng XI.

Bảng 7. Ngày bắt đầu và kết thúc mùa nóng với các suất bảo đảm khác nhau.

\begin{tabular}{lcccccc}
\hline \multirow{2}{*}{ Trạm } & \multicolumn{6}{c}{ Suất bảo đảm (\%) } \\
\cline { 2 - 7 } & \multicolumn{3}{c}{ Ngày bắt đầu } & \multicolumn{3}{c}{ Ngày kết thúc } \\
\cline { 2 - 7 } & $\mathbf{2 0}$ & $\mathbf{5 0}$ & $\mathbf{8 0}$ & $\mathbf{2 0}$ & $\mathbf{5 0}$ & $\mathbf{8 0}$ \\
\hline \multirow{2}{*}{ Thanh Hóa } & $01 / \mathrm{IV}$ & $15 / \mathrm{IV}$ & $24 / \mathrm{IV}$ & $21 / \mathrm{X}$ & $04 / \mathrm{XI}$ & $19 / \mathrm{XI}$ \\
Vinh & $30 / \mathrm{III}$ & $09 / \mathrm{IV}$ & $23 / \mathrm{IV}$ & $17 / \mathrm{X}$ & $03 / \mathrm{XI}$ & $17 / \mathrm{XI}$ \\
Kỳ Anh & $7 / \mathrm{IV}$ & $19 / \mathrm{IV}$ & $24 / \mathrm{IV}$ & $4 / \mathrm{X}$ & $8 / \mathrm{X}$ & $16 / \mathrm{X}$ \\
\hline
\end{tabular}

d) Tổng nhiệt độ

Tổng nhiệt độ là đơn vị biểu hiện thời gian sinh vật cần thiết cho thực vật hoàn thành một giai đoạn hay cả một vòng đời sinh trưởng và phát triển. Qua tổng nhiệt năm của một vùng có thể biết được khả năng gieo trồng được mấy vụ. Kết quả tính tổng nhiệt năm ứng với các suất bảo đảm khác nhau được thể hiện ở bảng 8 .

Bảng 8. Kết quả tính tổng nhiệt năm ứng với các suất bảo đảm khác nhau.

\begin{tabular}{lccccccccccc}
\hline \multirow{2}{*}{ Trạm } & \multicolumn{10}{c}{ Suất bảo đảm (\%) } \\
\cline { 2 - 12 } & $\mathbf{5}$ & $\mathbf{1 0}$ & $\mathbf{2 0}$ & $\mathbf{3 0}$ & $\mathbf{4 0}$ & $\mathbf{5 0}$ & $\mathbf{6 0}$ & $\mathbf{7 0}$ & $\mathbf{8 0}$ & $\mathbf{9 0}$ & $\mathbf{9 5}$ \\
\hline Thanh Hóa & 8962 & 8925 & 8785 & 8740 & 8672 & 8650 & 8608 & 8515 & 8493 & 8445 & 8358 \\
Vinh & 9130 & 9083 & 8966 & 8851 & 8807 & 8796 & 8692 & 8651 & 8591 & 8507 & 8480 \\
Kỳ Anh & 9245 & 9170 & 9049 & 8957 & 8886 & 8827 & 8771 & 8710 & 8635 & 8537 & 8477 \\
\hline
\end{tabular}

e) Nhiệt độ không khí tối thấp tuyệt đối trung bình năm

Nhiệt độ không khí tối thấp tuyệt đối trung bình năm là một chỉ tiêu quan trọng nhằm xác định ranh giới trồng các cây ăn quả và cây công nghiệp dài ngày. Kết quả tính toán cho các trạm đại diẹn được thể hiện trên bảng 9 . 
Bảng 9. Nhiệt độ tối thấp tuyệt đối TB năm tại một số trạm $\left({ }^{\circ} \mathrm{C}\right)$

\begin{tabular}{ccccccc}
\hline Trạm & Thanh Hóa & Tĩnh Gia & Vinh & Quỳnh Lưu & Hà Tĩnh & Kỳ Anh \\
\hline Tmin & 8,7 & 8,1 & 8,9 & 8,6 & 9,5 & 10,0 \\
\hline
\end{tabular}

\subsubsection{Tài nguyên mưa}

1) Phân bố mưa và đặc trưng mùa mưa

Lượng mưa năm ở khu vực nghiên cứu dao động từ 1600-2819 mm với tâm mưa nhỏ ở Kỳ Anh $(2819 \mathrm{~mm})$. Lượng mưa phân bố không đều, chủ yếu tập trung ở các mùa mưa, chiếm từ $60-70 \%$ lượng mưa năm. Mùa mưa vùng ven biển Bắc Trung Bộ bắt đầu vào tháng VII và kết thúc vào tháng $X$ ở khu vực giáp $\mathrm{DB}$ Bắc Bộ, càng dịch chuyển về phía Nam mùa mưa bắt đầu chậm hơn (tháng VIII - Kỳ Anh) và kết thúc muộn hơn (tháng XI hoặc XII).

Bảng 10. Tổng lượng mưa tháng và năm $(\mathrm{mm})$.

\begin{tabular}{lrlllllllllllll}
\hline \multirow{2}{*}{ Trạm } & \multicolumn{10}{c}{ Tháng } & \multicolumn{10}{c}{ Năm } \\
\cline { 2 - 10 } & \multicolumn{1}{c}{ I } & II & III & IV & V & VI & VII & VIII & IX & X & XI & XII & \\
\hline Thanh Hóa & 20,5 & 22,2 & 40,2 & 62,6 & 145,4 & 184,6 & 185,8 & 277,2 & 387,5 & 272,5 & 74,8 & 28,4 & 1701,6 \\
Vinh & 49,0 & 38,4 & 47,5 & 62,0 & 145,6 & 114,0 & 107,7 & 244,7 & 492,6 & 516,5 & 160,0 & 73,5 & 2051,4 \\
Kỳ Anh & 112,3 & 68,8 & 62,2 & 63,0 & 151,6 & 120,4 & 99,7 & 248,4 & 555,9 & 750,1 & 387,3 & 200,2 & 2819,9 \\
\hline
\end{tabular}

2) Ngày bắt đầu và kết thúc mùa mưa

Theo kết quả nghiên cứu KTNN [8] thì khi lượng mưa bằng lượng bốc thoát hơi tiềm năng $(\mathrm{P}=\mathrm{PET})$ là thời kỳ mùa mưa đối với sản xuất nông nghiệp và khi $\mathrm{P}=1 / 2 \mathrm{PET}$ là thời kỳ bắt đầu hoặc kết thúc giai đoạn ít mưa đối với sản xuất nông nghiệp. Kết quả tính toán thời kỳ bắt đầu và kết thúc mùa mưa, mùa ít mưa trên quan điểm KTNN ở một số trạm đại diện vùng nghiên cứu được thể hiện trên bảng 11 .

Bảng 11. Ngày bắt đầu và kết thúc mùa mưa ứng với các suất bảo đảm khác nhau (\%).

\begin{tabular}{lcccccc}
\hline \multirow{2}{*}{ Trạm } & \multicolumn{5}{c}{ Mùa mưa } \\
\cline { 2 - 7 } & $\mathbf{2 0 \%}$ & $\mathbf{5 0 \%}$ & $\mathbf{8 0 \%}$ & $\mathbf{2 0 \%}$ & $\mathbf{5 0 \%}$ & $\mathbf{8 0 \%}$ \\
\cline { 2 - 7 } & $18 / 04$ & $22 / 05$ & $20 / 06$ & $30 / 09$ & $25 / 10$ & $17 / 11$ \\
\hline Thanh Hóa & $22 / 05$ & $21 / 06$ & $11 / 08$ & $02 / 11$ & $23 / 11$ & $07 / 12$ \\
Vinh & $06 / 05$ & $23 / 05$ & $23 / 06$ & $17 / 11$ & $30 / 11$ & $12 / 12$ \\
Kỳ Anh & & & &
\end{tabular}

3) Thống kê lượng mưa tích luỹ trước và sau mốc được chọn

[6] chọn lượng mưa luỹ tích (tính từ thời điểm trung điểm mùa hạn) $75 \mathrm{~mm}$ là bắt đầu thời vụ gieo trồng hoa màu cạn, $200 \mathrm{~mm}$ là bắt đầu thời điểm làm đất cho một vụ lúa nước. Thời điểm kết thúc mùa mưa được ấn định bằng lượng mưa cộng lại từ thời điểm mốc về sau. Các tác giả nhận định rằng 500-300 mm luỹ tích về sau là thời điểm từ đó có thể trông mong có đủ nước để làm một vụ lúa thứ hai hoặc một vụ màu ngắn ngày với điều kiện là lúc gieo trồng phẫu diện đất phải đủ ẩm.

Bảng 12. Ngày lượng mưa tích luỹ đầu mùa và cuối mùa ứng với SBĐ $80 \%$.

\begin{tabular}{lccccc}
\hline \multirow{2}{*}{ Trạm } & \multicolumn{2}{c}{ Đã tích luỹ được } & \multicolumn{3}{c}{ Sẽ còn mưa } \\
\cline { 2 - 5 } & $\mathbf{7 5 m m}$ & $\mathbf{2 0 0 \mathbf { m m }}$ & $\mathbf{5 0 0 \mathbf { m m }}$ & $\mathbf{3 0 0 m m}$ & $\mathbf{1 0 0 m m}$ \\
\hline Thanh Hóa & $17 / \mathrm{IV}$ & $27 / \mathrm{V}$ & $28 / \mathrm{VIII}$ & $19 / \mathrm{IX}$ & $15 / \mathrm{X}$ \\
Vinh & $10 / \mathrm{III}$ & $17 / \mathrm{V}$ & $24 / \mathrm{IX}$ & $09 / \mathrm{X}$ & $07 / \mathrm{XI}$ \\
Kỳ Anh & $30 / \mathrm{I}$ & $30 / \mathrm{III}$ & $22 / \mathrm{X}$ & $05 / \mathrm{XI}$ & $24 / \mathrm{XI}$ \\
\hline
\end{tabular}


Như vậy, dựa vào bảng 12 có thể kết luận: có thể trông đợi cứ 10 năm thì có 8 năm vào tuần thứ 2 của tháng IV ở Thanh Hóa ít nhất cũng đã tích luỹ được $75 \mathrm{~mm}$ và đến tuần 3 tháng $\mathrm{V}$ đã tích luỹ được $200 \mathrm{~mm}$. Tương tự như vậy, từ tuần 3 tháng VIII sẽ còn mưa ít nhất $500 \mathrm{~mm}$. Từ tuần 2 tháng IX sẽ còn mưa ít nhất $300 \mathrm{~mm}$ và đến tuần 2 tháng $\mathrm{X}$ sẽ còn mưa ít nhất $100 \mathrm{~mm}$.

4) Xác suất 2-3 tuần khô liên tục

Ở những vùng khí hậu bất thường trong mùa mưa có thể xuất hiện những đợt khô ngắn, nhiều khi còn dự kiến khả năng có thể xảy ra một đợt khô liên tục 2-3 tuần trong mùa sinh trưởng của cây trồng. Nếu đợt khô đó trùng với một giai đoạn cây mẫn cảm, sự phát triển của cây có thể bị ức chế. Mặt khác, trong giai đoạn thành thục nhiều khi khô lại có lợi. Hình 3 cho thấy trong các tháng mùa mưa (tháng $\mathrm{V}-\mathrm{X}$ ) vẫn xuất hiện các đợt khổ hạn 2-3 tuần liên tiếp với xác suất từ $40-60 \%$ ở Vinh.

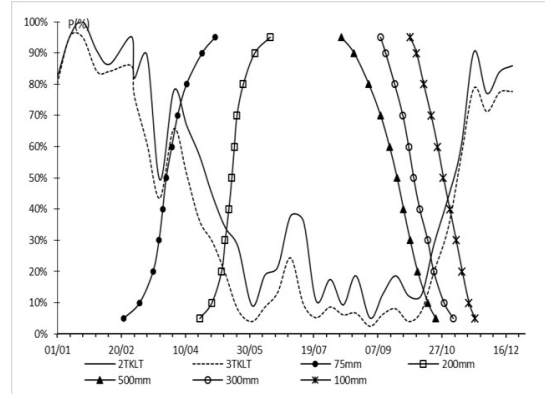

a) Trạm Thanh Hóa

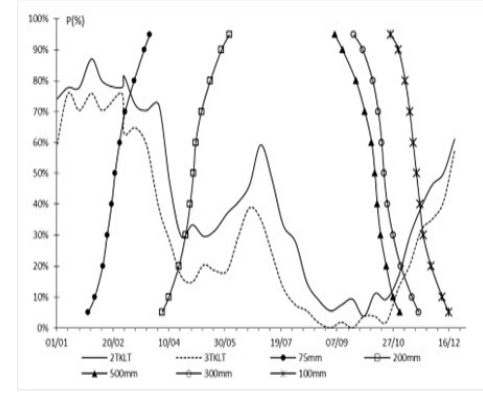

b) Trạm Vinh

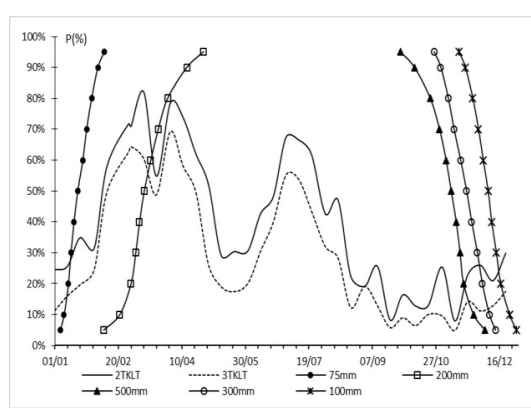

c) Trạm Kỳ Anh

Hình 3. Lượng mưa tích luỹ trước, sau và xác suất xuất hiện 2,3 tuần khô liên tục.

5) Sự phân bố của chỉ số ẩm

Trong mùa mưa nói chung lượng mưa tháng cao hơn lượng bốc hơi. Hệ số ẩm đều lớn hơn 1 cho nên trong mùa mưa lượng nước tự nhiên về cơ bản là thừa nước cho sản xuất nông nghiệp. Cụ thể sự phân bố của chỉ số ẩm trung bình tháng được thể hiện trong bảng 13.

Bảng 13. Chỉ số ẩm trung bình tháng.

\begin{tabular}{lcccccccccccc}
\hline \multirow{2}{*}{ Trạm } & \multicolumn{10}{c}{ Tháng } \\
\cline { 2 - 12 } & I & II & III & IV & V & VI & VII & VIII & IX & X & XI & XII \\
\hline Thanh Hóa & 0,4 & 0,4 & 0,6 & 0,7 & 1,1 & 1,3 & 1,3 & 2,1 & 3,4 & 2,8 & 1,0 & 0,5 \\
Vinh & 0,9 & 0,7 & 0,6 & 0,6 & 1,0 & 0,8 & 0,7 & 1,8 & 4,4 & 6,0 & 2,4 & 1,3 \\
Kỳ Anh & 2,0 & 1,2 & 0,8 & 0,6 & 1,0 & 0,8 & 0,6 & 1,7 & 5,0 & 8,6 & 6,1 & 3,6 \\
\hline
\end{tabular}

Bảng 13 cho thấy ở vùng ven biển Thanh Hóa có 5 tháng (từ tháng XII đến IV), vùng ven biển Nghệ An chỉ có 4 tháng và 2 tháng (III, IV) tại Kỳ Anh có lượng mưa không đủ cung cấp cho sản xuất nông nghiệp.

\subsection{Tác động của tài nguyên khi hậu nông nghiệp tới hệ sinh thái trồng trọt vùng đồng bằng ven biển Bắc Trung Bộ}

3.2.1. Tác động của điều kiện khí hậu đến sự phân bố và thời vụ cây trồng vùng nghiên cứu

- Trong vụ đông xuân

+ Đối với cây lúa có thể sử dụng các giống có thời gian sinh trưởng dài đến 125 ngày;

+ Cây ngô: thời vụ gieo ngô đông-xuân sớm: từ 10/10 đến $15 / 11$; đông xuân chính vụ: từ $15 / 12$ đến $20 / 1$.

+ Cây lạc: thời vụ từ ngày $1 / 1$ đến $30 / 1$; vụ xuân hè từ $1 / 2$ đến $28 / 2$. 
+ Đối với đậu xanh, thời vụ gieo từ $1 / 2$ đến $15 / 2$. Trên cây sắn, sử dụng giống KM94, thời vụ trồng từ $1 / 11$ đến $28 / 2$.

- Trong vụ lúa mùa:

+ Trên chân đất thường bị ngập úng, bố trí trà lúa né lụt để thu hoạch trước ngày 30/8; sử dụng các giống lúa cực ngắn, có thời gian sinh trưởng dưới 100 ngày. Bố trí cho lúa chín và thu hoạch trước ngày $5 / 10$; sử dụng các giống có thời gian sinh trưởng dưới 100 ngày. Đất chuyên trồng 2 vụ lúa/năm, sử dụng các giống có tiềm năng năng suất và chất lượng cao, có thời gian sinh trưởng trên 115 ngày.

Có thể nhận thấy:

- Trong 2 vụ mùa và vư đông xuân, các cây trồng có sự thay đổi rõ rệt. Trong vụ đông xuân, thành phần các cây trồng đa dạng hơn so với vụ mùa

- Cùng 1 cây lúa nhưng vụ đông xuân thường dùng các giống lúa có độ dài ngày hơn, các giống lúa có khả năng chịu hạn.

\subsubsection{Tác động của điều kiện khí tượng nông nghiệp đến năng suất cây trồng.}

- Xu thế năng suất lúa trong những năm gần đây:

+ Đối với lúa đông xuân: trong những năm gần đây năng suất lúa có xu thế tăng ở hầu hết các địa phương, trung bình mỗi vụ tăng từ $1.5-2$ tạ/ha.

+ Đối với vụ mùa/hè thu: năng suất thấp hơn so với vụ đông xuân và không thực sự ổn định như vụ đông xuân.

+ Đối với một số cây trồng ngô, lạc: năng suất không có sự biến độ nhiều, năng suất trong những năm gần đây dao động \pm 1 tạ/ha.

- Mối quan hệ năng suất với các yếu tố khí tượng nông ngiệp

+ Đối với lúa đông xuân: hệ số tương quan giữa năng suất lúa đông xuân với nhiệt độ trung bình không khí vào tháng III là cao nhất (hệ số tương quan $\mathrm{r}=-0,663$ và $-0,517$ ) và lượng mưa tháng II là 0,636 .

+ Đối với lúa mùa: có quan hệ chặt chẽ hơn cả là nhiệt độ trung bình tháng VIII, lượng mưa tháng $\mathrm{X}$ và số giờ nắng tháng VII

+ Đối với lúa hè thu: quan hệ giữa năng suất và lượng mưa tháng VII, số giờ nắng tháng VII và nhiệt độ trung bình tháng VI là cao nhất và lần lượt bằng $-0,61,-0,50$ và 0,52 .

+ Đối với cây ngô: vụ chính là đông xuân và vụ xuân: Nhiệt độ tối thấp từ giữa tháng XI đến đầu tháng $I$ có ảnh hưởng đến năng suất ngô $(\mathrm{r} \approx-0,33$ đến $-0,55)$ tuy nhiên từ giữa tháng I và tháng II mối tương quan lại đổi chiều với hệ số tương quan riêng giữa nhiệt độ tối thấp trung bình tuần và năng suất ngô từ 0,35 đến 0,49 . Đến giai đoạn trổ cờ-chín ngô vụ đông xuân (tháng $\mathrm{I}, \mathrm{II})$ và vụ xuân (tháng $\mathrm{IV}, \mathrm{V}$ ) thì lượng mưa ảnh hưởng tốt đến năng suất ngô $(\mathrm{r} \approx 0,42-0,78)$.

+ Đối với cây lạc: năng suất lạc tỷ lệ nghịch với nhiệt độ đầu vụ (tuần 3/I đến tuần 1/II (hệ số tương quan riêng từ $-0,36$ đến $-0,43)$, lượng mưa tuần $1-2 / \mathrm{II}(\mathrm{r}=-0,64)$ và lượng mưa cuối vụ (từ tuần $3 / \mathrm{V}$ đến tuần $3 / \mathrm{VII}$ ) với $\mathrm{r}=-0,57$ đến $-0,64$. Trong khi đó số giờ nắng đầu vụ (tuần $1-2 / \mathrm{I} ; \mathrm{r}=0,62)$ và giai đoạn cuối vụ - từ tuần $2 / \mathrm{IV}$ đến tuần $2 / \mathrm{VI}(\mathrm{r}=0,76)$ tỷ lệ thuận với năng suất lạc.

\section{Kết luận}

1) Vùng đồng bằng ven biển Bắc Trung Bộ có độ dài ngày dao động từ 10-11 giờ vào các tháng chính đông và $12-13$ giờ vào các tháng chính hè. Trung bình năm số giờ nắng dao động từ 1400-1800 giờ nắng. Bức xạ quang hợp trung bình năm là $56-61 \mathrm{kcal} / \mathrm{cm}^{2}$.

2) Điều kiện nhiệt và tài nguyên nhiệt là yếu tố khí hậu quyết định sự tồn tại hay không tồn tại của cây trồng, cơ cấu mùa vụ và luân canh cây trồng.

- Do chịu ảnh hưởng của gió mùa đông bắc nên khu vực nghiên cứu thường có mùa đông lạnh và có thời kỳ xảy ra các đợt rét hại ảnh hưởng đến sản xuất. 
- Tổng nhiệt năm của vùng nghiên cứu biến động từ $8.600^{\circ} \mathrm{C}$ đến $8.800^{\circ} \mathrm{C}$ với nguồn nhiệt này phần lớn diện tích vùng đồng bằng trồng được 2 vụ lúa.

3) Tồng lượng mưa năm vùng nghiên cứu dao động từ 1600-2800 mm và phân bố không đều theo không gian và thời gian. Do đó nên sử dụng:

- Ngày bắt đầu và kết lượng mưa tích luỹ đầu mùa và cuối mùa tương ứng với các giá trị $75 \mathrm{~mm}, 200 \mathrm{~mm}, 500 \mathrm{~mm}, 300 \mathrm{~mm}$ và $100 \mathrm{~mm}$ là cơ sở cho việc xác định thời vụ cây trồng trên các diện tích canh tác trông chờ vào mưa. Việc xác định 2-3 tuần khô, ướt liên tục rất hữu ích cho các nhà quản lý chỉ đạo sản xuất trong việc sắp xếp cơ cấu mùa vụ và tưới tiêu nước.

4) Do diễn biến của mùa mưa và xuất hiện của các loại hình thiên tai nên cây trồng vụ đông xuân đa dạng hơn vụ mùa. Trong những năm qua, năng suất và sản lượng của cây trồng trong vụ đông xuân ở khu vực nghiên cứu có xu thế tăng dần, điều này liên quan đến thiên tai trong vụ đông xuân không tác động đáng kể và các giải pháp canh tác ngày càng được cải tiến. Trong vụ mùa, năng suất và sản lượng cây trồng có tính biến động mạnh hàng năm, do thiên tai có tác động đáng kể ở khu vực nghiên cứu.

Đóng góp của tác giả: Xây dựng ý tưởng nghiên cứu: N.H.S., D.V.K.; Lựa chọn phương pháp nghiên cứu: N.H.S., D.V.K.; Xử lý số liệu: N.H.S. Viết bản thảo bài báo: N.H.S., D.V.K.; Chỉnh sửa bài báo: N.H.S.

Lời cam đoan: Tập thể tác giả cam đoan bài báo này là công trình nghiên cứu của tập thể tác giả, chưa được công bố ở đâu, không sao chép từ những nghiên cứu trước đây; không có sự tranh chấp lợi ích trong nhóm tác giả.

\section{Tài liệu tham khảo}

1. SRD. Tổng hợp một số hoạt động ứng phó với biến đổi khí hậu ở vùng đồng bằng sông Cửu Long. Báo cáo tổng hợp, 2013, 63-70.

2. Sơn, N.H.; Dương, T.H. Nghiên cứu, lựa chọn chỉ tiêu đánh giá và phân vùng khí hậu nông nghiệp khu vực Bắc Trung Bộ và Duyên hải Miền Trung. Tạp chí Khí tuoọng Thủy văn 2015, 655, 37-42.

3. Stigter, K. Applied Agrometeorology. 2010, pp. 1100. ISBN-13: 978-3540746973.

4. Viết, N.V. Tài nguyên khí hậu nông nghiệp Việt Nam. NXB Nông nghiệp, 2009.

5. Viết, N.V. Khai thác tài nguyên khí hậu nông nghiệp Việt Nam. NXB Tài nguyên Môi trường và Bản đồ Việt Nam, 2012.

6. Oldeman L.R.; Frere, M. Nghiên cứu khí hậu nông nghiệp nhiệt đới ẩm Đông Nam Á. Bản dịch NXB Nông nghiệp, 1988.

7. Cheng, C. Climate and Agriculture in China. China Meteorological Press Foreign Language Book No.108. 1993, pp. 519. ISBN 7-5029-1313-0/P.0572.

8. Jagtap, Shikant, S. Planning sustainable agriculture using agroclimatic database. WMO - CagM. 85. 2001.

9. Tuấn, Đ.T. Cơ sở khoa học của thời vụ gieo trồng. NXB Nông nghiệp, 1979.

10. Huỳnh, L.Q. Điều kiện khí hậu nông nghiệp đối với một số cây trồng chính ở đồng bằng Bắc Bộ, Trung Bộ và Nam Bộ. Báo cáo kết quả đề tài nghiên cứu khoa học. Viện Khí tượng Thủy văn, 1988.

11. Toàn, P.N.; Đắc, P.T. Khí hậu Việt Nam. NXB Khoa học Kỹ thuật. 1993.

12. Ngữ, N.Đ.; Hiệu, N.T. Khí hậu và Tài nguyên khí hậu Việt Nam. NXB Nông nghiệp, 2004.

13. Viết, N.V. Kiểm kê, đánh giá và hướng dẫn sử dụng tài nguyên khí hậu nông nghiệp Việt Nam. Báo cáo tổng kết đề tài nghiên cứu khoa học, Viện Khoa học Khí tượng Thuỷ văn và Môi trường, 2006.

14. Chinh, N.D. Kiểm kê, đánh giá tài nguyên khí hậu Việt Nam. Báo cáo kết quả đề tài nghiên cứu khoa học. Viện Khoa học Khí tượng Thuỷ văn và Môi trường, 2006.

15. Sơn, N.H. Nghiên cứu ứng dụng công nghệ viễn thám và GIS để phân vùng khí hậu 
nông nghiệp ở vùng Bắc Trung Bộ và Duyên hải miền Trung. Báo cáo tổng kết đề tài nghiên cứu khoa học, Viện Khoa học Khí tượng Thủy văn và Biến đổi khí hậu. 2016.

16. Niên giám thống kê tỉnh Thanh Hóa 2018. NXB Thống kê. 2019.

17. Niên giám thống kê tỉnh Nghệ An 2018. NXB Thống kê. 2019.

18. Niên giám thống kê tỉnh Hà Tĩnh 2018. NXB Thống kê. 2019.

19. Tân, P.V. Phương pháp thống kê trong khí hậu, NXB Đại học Quốc gia Hà Nội. 2005.

20. Jiukov, A.I.; Pelevoi, A.N. Những phương pháp toán học trong đánh giá tài nguyên khí hậu nông nghiệp. Len, 1999.

21. FAO. Crop evapotranspiration. Guidelines for computing crop water requirenments. FAO irrigation and drainage paper. No. 56. Rome, 1998.

22. WMO. Guide to Agricultural Meteorological Practices. 2010, 134, pp. 799.

\title{
Assessment of agro-climatic resources and its impates on crop- livelihoods in the North Central Coastal Delta region
}

\author{
Nguyen Hong Son ${ }^{1 *}$, Duong Van Kham ${ }^{1}$ \\ ${ }^{1}$ Vietnam Institute of Meoteorology, Hydrology and Climate change; \\ nguyenson.imh@gmail.com; kham.duongvan@imh.ac.vn
}

\begin{abstract}
Weather conditions and climate are closely related to crop livelihoods first of all light, temperature and water. These are indispensable elements and substitute for overall survival, growth, development and yields constitutes particular. Therefore, the evaluation of a system of agro-climatic conditions make the managers, directing production to capture the extent of the resource advantages of climate and of natural obstacles disaster, adverse weather caused to crop lvelihoods. The article uses data at meteorological stations in the study area and statistical methods to calculate and analyze the spatial and temporal evolution of agro-climatic features. Natural disasters and adverse weather and its impact on crop-livelihoods in the North Central Coastal Delta region. The results of the article will be the scientific basis for the development of agriculture in general and cultivation in particular in the study area.
\end{abstract}

Keywords: Agro-climatic resources; Impact on crop-livelihoods; North Central Coastal Delta region. 